\title{
Childhood Epithelioid Sarcoma
}

National Cancer Institute

\section{Source}

National Cancer Institute. Childhood Epithelioid Sarcoma. NCI Thesaurus. Code C8095.

An epithelioid sarcoma occurring in childhood. 